\title{
Trends in Philosophy of Mind and in Philosophy of Neuroscience
}

\author{
Juan José Sanguineti
}

School of Philosophy, Pontifical University of the Holy Cross, Rome, Italy

Published with permission of Springer Science + Business Media, 2015

In P. A. Gargiulo, H. L. Mesones-Arroyo (eds.), Psychiatry and Neuroscience Update. Bridging the Divide, Springer, Heidelberg 2015, pp. 23-37. DOI 10.1007/978-3-319-17103-6

\begin{abstract}
This paper presents current trends in philosophy of mind and philosophy of neuroscience, with a special focus on neuroscientists dealing with some topics usually discussed by philosophers of mind. The aim is to detect the philosophical views of those scientists, such as Eccles, Gazzaniga, Damasio, Changeux, and others, which are not easy to classify according to the standard divisions of dualism, functionalism, emergentism, and others. As the variety of opinions in these fields is sometimes a source of confusion, it is worth the effort to obtain an overall panorama of the topic. A general conclusion on epistemological and ontological issues, concerning the relationship between neurobiology and philosophy and the multi-level account of the embodied mind, is proposed.
\end{abstract}

Key words: Dualism, monism, behaviorism, functionalism, reductionism, emergentism, enactivism, mind, mental acts, self, body, soul, person.

\section{Introduction}

Philosophical questions concerning the nature of the mind and its relationship with the body are usually addressed by philosophy of mind. This area of philosophy inherits the traditional issue of the relationship between the soul and the body, interpreted in modern terms as the mind and the brain. Whereas the classical view of the problem was thoroughly ontological, going back to ancient philosophers as Plato and Aristotle, philosophy of mind, born in the twentieth century, is generally more epistemological, posing its object of inquiry within a scientific framework. Its topics are similar to those treated by the cognitive sciences, such as neurobiology, computational science, and cognitive psychology. 
These topics, namely perception, sensations, emotions, memory, language, thought, and free will, were typically considered by psychology. Scholars in this area face also questions concerning the nature of the mind and the meaning of the human person, who is seemingly constituted of mental capacities and neural processes, two dimensions related to the classical duality of soul and body.

The novelty of philosophy of mind, compared with classical psychology, is that the problem is tackled in strong relationship withthe natural sciences. Two candidates in dealing with psychological notions such as thought, intelligence, decisions, and representations, are neuroscience and computational science. Neuroscience studies and explains from an empirical perspective all that was typically reserved to psychology. Computational science seems capable of reproducing and dominating representations and thought processes. Accordingly, it seems natural that philosophy of mind will turn out to be a kind of philosophy of neuroscience and of philosophy of computation, although more essentially the former, if we take into account the recent development and prestige of neurobiology regarding human problems. This is clearly demonstrated by the proliferation of "neuro-disciplines", such as neurophilosophy, neuroethics, neurotheology, neuroeconomics, neuroaesthetics, and the like.

The difficulty with the resulting discipline is that it does not share the facility of the older metaphysical psychology in acknowledging a spiritual dimension to the human person. As human thought appeared to be immaterial or not physical, psychology maintained classically a good relationship with theology. To think of God as an immaterial being and then to speculate on the immortality of the human soul beyond the destruction of the human body was very natural for many authors. But in contemporary philosophy of mind these issues appear more problematic, because ontological concepts, such as being, form, and essence, do not seem to be available in the general scientific environment, whereas scientific concepts, dealing with physical, chemical, and biological concepts, are very familiar to scholars. Subsequent to the Kantian revolution, metaphysics was viewed with suspicion by philosophers and scientists, while the natural sciences became more consolidated and capable of vindicating the privilege of truth. Consequently, the classical philosophical problems had to be investigated in dialogue with the natural sciences, and sometimes in 
subordination to them. This is the present epistemological condition of philosophy of mind and philosophy of neuroscience ${ }^{1}$.

According to this scenario, the first and perhaps most important problem of philosophy of mind and neuroscience is the alleged distinction between mental and neural acts or events, while the second problem, provided the distinction is accepted, is their causal mutual relationship. These two main philosophical questions are answered differently by a series of standard positions: dualism, neural monism, functionalism, emergentism, and non-reductive physicalism.

This chapter will attempt to briefly present these positions, and to combine them with what can be understood as the philosophical thought of authors dealing with neuroscience rather than with a pure philosophical speculation. Many other problems, such as the relationship between neurobiology and philosophy, the extent of human freedom, the assessment of human actions in ethical issues, the particular orientation given to psychiatry, or the focus of educational efforts, depend essentially on the solution given to these fundamental questions.

\section{Standard Positions in Philosophy of Mind}

Philosophers of mind normally display an array of similar positions concerning the mind-brain duality. These different views can be found in any textbook on philosophy of mind ${ }^{2,3,4}$. My presentation attempts to go to the root of the problems and to indicate what I consider most relevant for the aim of this book. My account is clearly favorable to some kind of moderate dualism. I do not aim at being neutral on this issue.

The positions can be delineated within the following lines.

2.1. Dualism ${ }^{5}$. This traditional thesis claims that the human person is constituted by two kind of realities: one material and the other spiritual. In substantial dualism, the spiritual reality, known as the soul, spirit, or the mind, moves and guides the body, but it can also be affected by the latter. There is also the possibility of interaction between the soul and the body. Such a duality is attributed to animals and even to plants by Aristotle. 
If the body and the soul are not understood as substances, they can at least be viewed in terms of properties, as is elaborated in property dualism. This kind of dualism considers a group of human actions processes and operations as material because they are empirically verifiable, whereas others, such as thoughts, intentions, and desires, are categorized as immaterial because they are experienced as qualia, completely deprived of material properties. Similar to the assertion of substantial dualism, here it is claimed that spiritual operations move or guide bodily processes: a human agent as such, him or herself, wants to move the hand, and thus moves it.

Dualism can be held either phenomenologically or by common sense. It is very intuitive to experience our thoughts, feelings and decisions as something radically different from spatial material objects. Dualism can be also sustained by religious beliefs, and indeed, religion would be devoid of sense if all that exists were purely material. Materialism and atheism are intrinsically linked ${ }^{6}$. Finally, dualism can be argued and explained in philosophical terms.

In spite of the various philosophical accounts of the soul-body or mind-brain duality, dualism is a strong and persistent conviction held by many people since it corresponds to direct knowledge, or to what could be nominated the common sense perspective. Even the most rigorous materialists cannot avoid to experience thoughts and consciousness. The efforts made to reduce all reality to material reality are normally too complicated. They must be argued again and again, struggling against what constantly reappears in common language and implicit belief. For example, think of the paradox of saying: "I think that this $I$ does not exist".

2.2. Naturalism or physicalism. According to this position, nothing other than material substances or material properties exists. The apparent existence of mental acts must be reduced to something material, and this is why naturalism, or materialism, is often reductionist since it is committed to the effort of reducing an alleged entity to something different. Reductionism is also shared by what I will later call neurologist monism. The attempt to eliminate the notion that is reduced corresponds to the so-called eliminativism ${ }^{7}$, advocated by Paul and Patricia Churchland $^{8,9}$. 
A reduction aims at being an explanation ${ }^{10}$. Thus, materialists typically argue that a thought is nothing but a neural circuit and that this circuit explains the presentation of a thought. This epistemological procedure is taken from physics. The phenomenical presentation of light, for example, can be reduced/explained to electromagnetic waves. The reduction is correct, but the phenomenal light -the light as we see it-still remains a fact a psychological or a mental fact.

Notwithstanding the efforts to reduce the psychological process of vision to neurophysiological events, the phenomenon is not eliminated, so the duality between psychological and physical events persists. This is the paradox of physicalism, in its concern with reducing and eliminating the existence of mental properties.

Naturalism or physicalism ${ }^{11}$ has its roots in the prestige of physical explanations. The reason that sustains the widespread materialistic belief is mainly epistemological. Physics deals with spatio-temporal objects, ultimately testable by empirical procedures, which are based upon what can be detected by external senses or by public instruments of observation. Therefore, non-observable entities as such will never exist, though they could be postulated as instrumental logical devices, such as physical laws or mathematical spaces, capable of explaining physical phenomena.

The physical universe of discourse -the world as is viewed by physics- here is understood as closed or exclusive. Nothing can be postulated outside of this framework. God, the angels, souls, and mental entities are rejected because they do not fit into the ontological framework of natural sciences. Of course, it can be said that the world as it is seen by physics is an abstraction, because it is the result of selecting a series of basic properties (mass, space, movement, time, force) as a methodological choice for the explanation of all phenomena. In this sense, natural science is a partial view of reality. It does not comprehend reality as a whole ${ }^{12}$.

Paradoxically, even sensations, the so-called qualia in philosophy of mind, are problematic for materialism. Psychological acts and states do not belong to the realm of physical and observable events ${ }^{13}$. Accordingly, psychic events, such as acts of vision, pain as a sensation, and so on, should be ruled out by being reduced to neurophysiological events that can be detected by our external senses or by instruments of observation. 
For instance, the sheer sensation of pain cannot be externally observed. Pain, no doubt, is quite physical, but as such it does not belong to the universe of discourse of physics. If this universe is taken as exclusive, then pain becomes problematic and has to be reduced, and as a psychological act it will be understood as nothing. Hard materialist philosophers view the psychological world with suspicion because they rightly feel that to accept that world could lead to the acknowledgment of something beyond matter. They opt to protect the choice of remaining within the closed natural scientific world.

Now, how can reduction be accomplished? On one side, there is the notion that is supposed to be reduced, which in this case is the psychological reality: perception, representation, emotion, comprehension, or the Self. On the other side, some physical features (some functions of the human body) must be chosen as the matter to which the psychological events are supposed to be reduced. Three candidates are available for this operation: external actions and reactions, neurobiological processes, and computational procedures. So we have three possible positions.

2.2.1. Behaviorism. Internal actions are behaviorism's preferred object of reduction. Internal operations or states, such as emotions, decisions, and perceptions, have always some relation to external actions, or at least they can be ascertained through external reports and tests, so it is not difficult to attempt to assimilate the former within the latter. Accurate analyses, however, demonstrate that these two different types of acts are not equivalent.

Philosophical behaviorism ${ }^{14}$, though not always known by this name, aims to translate internal acts into behavioral dispositions. Psychological behaviorism, instead, follows the scheme of stimulus/response, and the associated notions of reinforcement and reward. In both cases, dualism is supposed to be avoided. As is well-known, psychological behaviorism was eclipsed by cognitive psychology. Even so, this psychological school was not without fruit since it demonstrated the importance of paying attention to behavior when attempting to study and to follow psychological states.

2.2.2. Neurologist monism. The reduction of mental acts to neurobiological processes might seem a more promising proposal. Perceptions, sensations, feelings, 
and conscious or unconscious cognitive states normally show a clear neural basis. The acts of vision, touching, smelling, and the others associated with the senses can be described and explained in neurological terms. It can be claimed at least that mental acts have always some correlative kind of neural acts or states. This kind of correspondence is often considered under the category of supervenience ${ }^{15}$. The correspondence between both dimensions must be defined in very precise terms, which is not an easy matter.

Neurologist monism claims that a psychological act is nothing more than a neurobiological event. This denomination is mine. Currently there does not exist a special name for this trend of thought in philosophy of mind, which at other times was known as the identity theory. This position seems to be similar to what I have called naturalism and can be seen as the most frequent version of naturalism in our times. Though many authors take for granted that this is the correct solution to the problem, the difficulties of this position have already been highlighted above. There is no doubt that the neurological dimension of psychological acts is essential, but it can also be demonstrated that it is partial. To perceive, to be conscious, is not exactly the same as a purely neural event.

2.2.3. Computational functionalism. The third attempted reduction springs from computational science and could be indicated as computational functionalism ${ }^{16}$. This position apparently goes beyond reductionism as understood in neurologist monism and behaviorism. It seems to recognize a certain immaterial content inside the alleged black box of the internal acts. Functionalism in philosophy of mind is, in general terms, a sophisticated position that equates mental states with causal roles or functions ${ }^{17}$. The supporters of this position do not accept the simple experience of feeling as a decisive feature of mental acts. Pain, for instance, should be rather defined functionally. This approach is not necessarily incompatible with the acknowledgement of qualia as real internal experiences. Now the reductionist move appears clearly in computational functionalism. Mental acts could be identified with computational functions or with information processing.

The key word here is information, which has several meanings connected with the transmission of messages and causal effects. Generically, information implies order in nature, an order introduced within an energetic physical basis. Order is a 
functional notion related to a certain goal to be attained through a particular arrangement of elements in space and time. Living organisms have the capacity of controlling information, received from the environment and transmitted to the different parts of the body in order to maintain the typical self-organization that characterizes the living system. When this information control is associated with cognitive representations, for example with perception, then the living system, endowed with a nervous system for that purpose, is called an intentional or a cognitive organism. This is the case of animals and humans. However, it is possible to separate the flow of information from its natural basis and to treat it using an artificial device (a computer). This procedure is a calculation, namely a transformation, according to an algorithm, of some inputs into certain outcomes.

It is tempting to say, then, that psychological operations or states should be just computations. Here inputs can be connected with outputs in a certain system through different computational procedures, as is typically done by computer. Computational devices are able to capture informational processes occurring in the physical world, particularly in organisms and brains, and to freely manipulate them so as to simulate and emulate natural or intentional processes, such as biological processes, diseases, perceptions, problem-solving, and decision-making. The task of the brain would be similar to the operations of a computer.

Computational functionalism was strongly stimulated by the development of artificial intelligence and robotics. But a new sort of dualism, namely between software and hardware, has now appeared, especially because the software, corresponding to the mind, is multiply realizable in different physical media (e.g., a brain, a standard computer, a quantum computer, etc.). Therefore, the computational mind appears to be independent from its bodily realization.

The problem with functionalism is that it concedes too little importance to the neurobiological basis of psychological states. It is easy to produce pieces of information manifoldly, just as a book can be printed or registered in any kind of computer. But this is not the case in a real cognitive operation or in an emotional state. Two persons may share the same thought, such as $2+2=4$, but nevertheless each one of them has a personal thought. 
This is the reason why neurobiologists normally pay little attention to computational functionalists. Engineers and computer scientists, instead, are more attracted by the functionalist proposal. The computational theory of mind favors the idea of a possible introduction of consciousness into a computational machine. But what kind of consciousness would a robotic consciousness be? It would be an imitation, not a real psychological state. Functionalism takes one aspect of mental states, the informational one, and ignores those states of lively action performed by real persons. In this sense, functionalism is a new form of reductionism.

2.3. Emergentism and antireductionism. The recognition of irreducibly higher levels in a stratified natural universe -life over non-life, sensitive consciousness over life, and human reason over sensitive consciousness- produced in the twentieth century the anti-reductionistic position called emergentism. This position emphasizes the existence of new kinds of properties emerging from the construction of lower layers, provided they are organized in a certain way ${ }^{18}$. Namely, mental states naturally emerge from a precise organization of neural integrated circuits.

There can be strong or weak versions of emergentism. The strong versions are not far from a moderate dualism, such as that found in Popper ${ }^{19}$. The weak versions (Bunge $)^{20}$ interpret the emergent properties as new global structures constituted by the assembly of many parts. The whole is more than the sum of the parts, as a house is more than a pile of bricks. John Searle ${ }^{21}$ seems to follow an intermediate position.

One of the problems faced by emergentism is the difficulty of providing an account of the causality between mental and neural events. Clearly the neural basis enables the subsistence of psychological states, and when this basis fails to function, impairment and disorders follow (bottom-up causation). However, it seems that also insights and decisions, for instance, the ideas flowing through my mind that cause me to write these lines, spontaneously select many brain activations in very specific areas (downward causation). Musical performance and linguistic abilities are responsible for specific brain activations and shape cerebral patterns in several ways. Emergentists usually stress downward causation while attempting to avoid interactionism in a dualistic sense. They criticize all types of reductionism, whether neurologist or functionalist. 
Connections that give rise to correct sounds or utterances are reinforced during the learning process, while those that produce the wrong results are not; and the difference is determined by the semantic rules that govern the systems. In this sense, certain connections within the brain, as well as with nerves and muscles, are selected and shaped through a process of downward causation: from the contents and meanings of the musical and linguistic signs, according to the semantic rules of musical notation and ordinary language, to neural and neurophysiological connections. To this extent, content and meaning, which, as externalism has it, go beyond the individual's brain and bear an objectivity of their own, are causally responsible for the actual shaping of the neural connections and networks required for a competent musical or linguistic performance ${ }^{22, \text { p197-198. }}$.

\section{Neurophilosophical Proposals}

Besides the official philosophers of mind, neuroscientists who are sensitive to humanistic topics frequently present opinions on epistemological and anthropological items concerning the problem of mind and brain, the nature of knowledge, human identity and free will, and other themes that justly correspond to the philosophical domain, even in ethics and religion. Their observations on these questions are sometimes episodic or very brief and frequently found in popular books. However, in other cases, they can be more systematic, ambitiously delineating a complete view of man. Their reflections can be located on the frontier between science and philosophy. They convey an amount of useful information regarding neuroscientific achievements and usually enter the philosophical field without the sophistication of professional philosophers. Hence, they risk being naïve in subtle matters or unduly mixing what can be scientifically demonstrated with what needs careful philosophical argumentation. In spite of these difficulties, the contribution of these authors to the philosophy of neuroscience is undeniable and can be considered complementary to the philosophers' efforts in the corresponding areas.

It is not easy to identify clear-cut positions among the authors involved in these neurophilosophical writings. Some of them more directly engage the current problems in philosophy of science and propose a solution. The solution may be dualistic, as in the case of Eccles, which is currently rather exceptional, or materialistic. Quite a number of them share a less than well-defined naturalistic background. While they usually reject a drastic dualism, being open to some form of imprecise non- 
reductionism, they contemporaneously include neurophysiological items that can enrich the anthropological view. Two other related areas of research are neuroethics and the so-called neurotheology. The former studies not only the problem of the legitimacy of deep neural interventionsin human beings, with their consequences for personality and society, especially in the areas of health, education, marketing, and culture, but also the biological foundations of ethical inclinations and actions. Neurotheology is concerned with the correlations between religious experiences and brain activations. Depending upon their philosophical position, namely, either materialistic or perhaps open to the spiritual dimension of man, authors involved in these areas sometimes draw contrasting conclusions regarding the distinction and causality between mind and brain.

Without any attempt at classification, this section will sketch out in broad lines those authors and insights which can be viewed as paradigmatic of these positions and as an expression of the major concerns and attitudes on the topics considered in this pages.

Before continuing with these points, it can be good to mention certain ideological movements, such as antipsychiatrism and transhumanism, which have had an impact on many questions debated by neuroscientists and philosophers of neuroscience.The antipsychiatric movement evaluates standard psychiatric practices very negatively, partially in reaction to certain abuses, but also due to the specific vision of man of many of its followers. One aspect of this negative evaluation can be illustrated in the criticism of the very concept of psychiatric disorders (definition, classification, and treatment), something which is linked to the patients' relationship with society. A balanced account of these topics must be considered in an overall philosophy of psychiatry ${ }^{23}$. Transhumanism claims that neural and genetic human enhancement of our abilities and potentialities are to be promoted even to the point of changing our species in the future into another, better post-human trans-species ${ }^{24}$.

These movements, such as those dealing with fundamental ethical questions, involve an evaluation of the risks and benefits of medical and psychiatric interventions in the brain, both by means of pharmaceuticals and through computational interfaces. Positions regarding this problem range from optimistic 
views, which soar to unlimited heights or to the transhumanism, to cautious and sometimes pessimistic caveats.

The assessment of what contemporary neuroscience enables us to do in human and social affairs creates many challenges in social policies, in education, in medicine, and ultimately depends upon some basic views held by philosophical anthropology. Ethical codes and prudential practices are not enough unless we go to the ontological and anthropological root. In this sense, philosophy of mind and of neuroscience could be considered a crucial part of anthropology. In the following pages, the basic positions on this theme shall be presented, especially in some selected authors.

3.1. John Eccles (1903-1997) was awarded a Nobel Prize in 1963 for his work on synaptic transmission. He was a disciple of Charles Sherrington (1857-1952), another Nobel Prize winner for research on neuron functions. Eccles ${ }^{25}$ held a clear dualistic position, which he shared with Sherrington ${ }^{26}$ and in some aspects with his colleague Robert Sperry ${ }^{27}$ (1913-1994), whose philosophical position is rather emergentist (Sperry won the Nobel Prize in 1981 for his studies on split-brain). The distinction between dualism and strong emergentism is not always clear-cut. In practice, Sperry diverges from Eccles only because the former does not believe in the survival of the immaterial mind after death. Popper's philosophy, wholeheartedly followed by his friend Eccles, is likewise akin to Sperry on this point.

According to Eccles ${ }^{25,28}$, there is no way of explaining the unity of human selfconsciousness and its active role in guiding the conscious experience without thepresence of an immaterial entity, called the self-conscious mind. This immaterial entity is capable of interacting with cerebral networks and, more specifically, with the dominant linguistic hemisphere (normally the left) at the cortical level. The mind is the source of the continuous selective integration of various activated neural centers that are continuously reorganized (spatio-temporally) during the state of wakefulness. The self-conscious mind, which is the root of personal identity, plays a central role in the conceptual interpretation of the information it receives from cerebral patterns as well as a role in guiding attention in order to focus perception, to awaken memories, and to promote active voluntary movements of the body by acting upon several cerebral open modules. Eccles ${ }^{25}$ estimated that this conjecture should not be rejected 
as anti-scientific, provided one accepts that it is normal in neurobiology to take into account psychological immaterial concepts, such as intelligence, comprehension, and the unity of the self.

3.2. Michael Gazzaniga (1939) worked under the guidance of Sperry in splitbrain research. He stressed the importance of the dominant left hemisphere in the process of verbally and consciously integrating representations arriving from the various cerebral modules. He also studied to what extent patients with perceptual disorders resulting from cerebral damages tend to confabulate rational explanations of incoming data in a coherent way. This task is attributed to a specific area of the left hemisphere,where he places a so-called interpreter. Corresponding to the linguistic consciousness emerging in the left hemisphere, the function of this hemisphere is extended to the creation of all human beliefs and to the manipulation of the different "selves" -sometimes in conflict- that pertain to other regions of the brain, in order to maintain the appearance of one self with its own story and identity. This operation requires a special skill in order to alter memories so as to adjust them to the dominant self. In this sense, in Gazzaniga, what happens as a pathological confabulation in the case of impaired perceptions, as when someone does not perceive a leg as his own, rather attributing it to someone else, is transformed into a universal procedure for the production of ideas and beliefs, even in the ethical and religious domains ${ }^{29,30,31}$. This position, although emergentist, is actually not far from materialism since the interpreter is simply produced by the left hemisphere.

The interpreter constantly establishes a running narrative of our actions, emotions, thoughts, and dreams. It is the glue that unifies our story and creates our sense of being a whole, rational agent. It brings to our bag of individual instincts the illusion that we are something other than what we are. It builds our theories about our own life, and these narratives of our past behavior pervade our awareness ${ }^{32, \text { p174. }}$.

There is something unintelligible in the notion of the interpreter in Gazzaniga. It is a creator of everything that one thinks in relation to himself and to the world, a fictional person that does not truly correspond with oneself. To say that this person is generated by the left hemisphere is a very obscure statement. We can understand that brain injuries produce pathological perceptions, but it is vacuous to say that the brain 
generates ethics, philosophy, religion, etc. Paradoxically, dualism is resuscitated, but in a strange way: the dualism of the interpreter and the brain.

3.3. Jean-Pierre Changeux (1936-), a well-known French neurobiologist, studied those allosteric mechanisms involved in the function of nicotinic receptors and related to cognitive functions. On the basis of these studies, he formulated a theory of epigenesis by synapse selection. He also proposed a theory on the global neuronal workspace, which was associated with consciousness. A great humanist, Changeux published several books on the neuronal basis of cognitive and affective consciousness as well as on neuroaesthetics ${ }^{33}$. He was also interested in the problem of the biological foundation of ethics. His concern for certain topics, such as religion, ethics, cognition, truth, beauty, and the good, brought him close to the field of philosophy.

Changeux adheres to an "enlightened" materialism, claiming that the neural structure of $\operatorname{man}^{34}$ is sufficient to explain consciousness, ideas, love, and ethical problems, such as the need for tolerance and reciprocal respect, human rights and obligations, and even the existence of a universal natural ethics based on fraternity, freedom, and peace. The idea that there is something beyond the human body, spirit or mind, must be abandoned as useless and anti-scientific.

It is difficult to understand how can Changeux believe that he is able to draw his ethical convictions from neurobiology. In a book published together with the philosopher Paul Ricoeur, entitled, What Makes Us Think ${ }^{35}$, the latter tries unsuccessfully to convince Changeux that the neurobiological perspective is partial and insufficient in providing a real foundation for ethics, unless one previously has ethical convictions. There is a fundamental methodological obscurity when too many human achievements are supposed to be simply the result of the structural and functional dynamics of our nervous system. This point will be highlighted by the following two authors.

3.4. In 2003, Maxwell Bennett (neurobiologist, 1939-) and Peter Hacker (philosopher, 1939-) published a book on the philosophical foundations of neuroscience ${ }^{36}$, a publication which was quickly followed by another in 2008 on the history of cognitive neuroscience ${ }^{37}$. They asserted that too frequently many 
neuroscientists uncritically attribute to the brain, or to parts of the brain, psychological acts that should properly be assigned to the person. To say that the neurons perceive, that a neuronal circuit decides, that our hippocampus remembers, or that some cerebral region interprets is not false, but rather nonsense. This kind of discourse is a mereological fallacy, referring to the parts what should be ascribed to the person, which is not a mere sum of the parts.These authors aim at bringing some conceptual clearness to cognitive neuroscience, in order to avoid reductionism and materialism based upon an abuse of language.

We do not know what it means to say that the brain thinks, fears or is ashamed ${ }^{37}$, p255.

These authors accept that we understand, love, or perceive, thanks to the brain, but not that the brain itself is the subject of those acts. Neuroscientists can discover that some neuronal events are related to psychological acts, but nothing more. Bennett-Hacker are not dualistic since they also deny that psychological operations should be referred to consciousness or to the mind.

To ascribe a mind to a creature is to say that it is a creature with a distinctive range of capacities: in particular, capacities for concept-exercising thought, selfconsciousness, memory and will ${ }^{37, p 13}$.

These are the capacities that confer the status of person. But the authors do not develop a theory of the human person, nor do they explain in what sense the brain is causally responsible for our psychological acts. Their position seems to be close to Aristotelian-based views.

It would be better to say, with Aristotle, that human beings are ensouled creatures (empsuchos) -animals endowed with such capacities as confer upon them, in the form of life that is natural to them, the status of persons ${ }^{37, \mathrm{p} 262}$.

3.5. Neuroscientists contributing to improve the anthropological view of man. Neurobiologists, including those already mentioned, sincerely think that they contribute to a better knowledge of man, and they certainly accomplish this task. This section will refer to certain neurobiologists whose discoveries and theoretical reflections, independently of a more or less clear account of the specific topic of philosophy of mind, make specific contributions that could quite well be integrated 
into a philosophical vision of the human person. These discoveries and reflections necessitate, needless to say, further discussions and adjustments. What is more encouraging, the list could be very long; however, the constriction of space limits us to a brief selection.

Antonio Damasio (1944-) investigated the role of emotions in knowledge, specifically in the basic psychosomatic levels of human consciousness. His work delineated a new picture of primary and secondary emotions, moods or background affective states, and feelings. He proposed useful distinctions between an unconscious protoself, linked to the overall state of the organism, a higher core consciousness, and the Self, based upon an extended or autobiographical consciousness ${ }^{38}$. The interplay between consciousness, body and feelings, with relation to the environment, is far from the older simplistic views that go back to the rationalistic account of man and to Descartes. This interplay is a dynamism addressed to the consolidation of homeostatic states tending to "the good life" of the human person. Damasio's philosophical preference in philosophy of mind tends towards Spinoza rather than to Descartes: the mind is like the "idea of the body"

Gerald Edelman (1929-2014), winner of the 1972 Nobel prize for his studies on the immune system, developed a theory of human (and animal) cognition and its neural substrate, based upon an idea that can be labeled as neural Darwinism. This hypothesis posits a spontaneous neuronal process of selection between populations of neurons, in contraposition to the idea of information processing by instructions ${ }^{40}$. Leaving aside technical details, this hypothesis is convergent with research on epigenesis through synapse competition in Changeux.

Another major thesis in Edelman is the role of mapping in brain activity, which at some level of the brain is a way of creating representations of the objects perceived, similar to the mapping of the human body contained in the somatosensory area of the cortex. There is a continuous re-entry or informational exchange between brainmaps receiving various kinds of information from different areas (this point is convergent with Damasio's views on the same topic).There are also brainmaps of maps, a process that explains the formation of concepts, memories and learning, beginning with the aforementioned Darwinist principle of selective competition between brain synaptic patterns $^{41}$. 
In the same vein, Christof Koch and Giulio Tononi investigated the neural correlates of consciousness (NCC). Tononi holds that the basic substratum for being conscious, i.e., awake, is a wide group of selected neurons firing together according to adequately synchronized oscillations associated with the talamo-cortical system ${ }^{42,43}$. The NCC is not a special area, but a talamo-cortical network distributed throughout the brain. This theory

introduces a measure of integrated information called $\phi$, quantifying the reduction of uncertainty (i.e., the information) that is generated when a system enters a particular state through interactions among its parts, above and beyond the information that is generated independently within the parts themselves (hence integrated information) $)^{44, \mathrm{p} 254}$.

This measure quantifies the neural requirement to be conscious in a context of biological complexity and provides the possibility of explaining unconscious cognitive states, such as that linked to nearly automatic behavior, while opening the way to deeper cognitive unconscious states corresponding to creative prerepresentational states.

Cognitive consciousness has to be completed with affective consciousness. This new understanding of consciousness became Joseph LeDoux's (1949-) object of research. He considered neural dynamisms connected with basic emotions to be linked to animal survival, nutritional, and sexual behavior ${ }^{45}$. His research was complementary to that accomplished by Damasio. Jaak Panksepp (1943-), who coined the expression affective neuroscience, presents an ambitious scenario in animal behavior, integrating complex emotional systems, such as seeking, pleasure, pain, panic, rage, anger, and anxiety ${ }^{46}$. These systems, based upon instincts, are unconscious, but have conscious manifestations. They are realized through neural circuits related to meaningful stimuli that have an impact on perceptual systems and preside over behavioral responses, such as defense, attack, and the search for food. The whole of these systems constitutes the affective dimension of consciousness, which is rooted in subcortical brain levels with projections into the cortex. Panksepp advocates the existence of an unconscious affective Self, involving subcortical and cortical regions, both in animals and in humans. 
The thought-provoking experiments performed by Benjamin Libet (1916-2007) had a special impact on the neurophilosophical discussions on consciousness. A person is asked to freely move his or her finger or hand at any moment within a range of time, and to tell, by pressing a button, the exact moment in which he or she was aware of the decision to perform the motor action. Electronic devices detect the correlated neural activations and the movements of the muscles. The result was the delineation of a specific neural firing called readiness potential, which briefly preceded (nearly one second, but in later experiments even longer) the awareness of the decision ${ }^{47}$.

A quick reductionistexplanation of this experiment, such as "the brain decides for us", can arguably be avoided, when the conditions and limitations of this experiment are analyzed. Simultaneously, insights on the role of previous unconscious preparations for decisions can be drawn. The experiment also provides a better understanding of the different levels of voluntary actions, some of which can be clearly planned, while others can be accomplished in a semi-automatic way. These neuropsychological findings leave the nature and the relationship between consciousness and will open to debate.

Another discovery in neurobiology, important for its potential implications in the philosophy of man, refers to the mirror neurons. This topic has become very popular, finding a place in books and magazines and providing an occasion for speculation and debates in many fields. The fact that the observation of meaningful or teleological actions accomplished by other subjects provokes the firing of sensorymotor specific neurons in the observer seems to indicate that the observer mimics the actions of others, at least in imagination. In this sense, there is a kind of natural participation in what people see or perceive in others' actions and passions, such as pain. This form of knowledge is relevant for anthropological topics, such as empathy, which is theorized by phenomenologists, and also for a better comprehension of the process of learning by imitation ${ }^{48,49}$.

Some authors consider this discovery a breakthrough in the history of neuroscience ${ }^{50}$. Obviously, mirror neurons cannot be made responsible for the entire framework of personal interrelations. However, if integrated with many other aspects of brain dynamics, they do play a role in an account of the human and animal mind 
and consciousness in which relations, even from the prenatal period, must be put at the center of the human person and in his or her development in cognitive and affective states. Accordingly, family, friendship, and society appear to be essential in evolving human life. This idea is far from that of the traditional approach which tended to view mind and brain as isolated items.

From the previous convergent neurobiological accounts concerning consciousness, some comprehensive conclusions can be drawn. These provide a whole vision of the human person, under the various labels of the emotional brain, the social brain, the empathic brain, and the like. To these aspects touching upon the higher levels of the embodied mind, as it is often called, there can be added rational as well as emotional dimensions regarding ethical and religious behavior inasmuch as they can be followed in their cerebral expressions.

Neuroethics, both theoretical and empirical, the latter using functional magnetic resonance imaging (fMRI), considers, among other things, the interactions between cortical and subcortical networks in the brain, attempting to assess their weight in moral reasoning, judgments, desires, and impulses related to ethical behavior ${ }^{51,52,53,54}$. Another field of interest in neuroethics is the cerebral corresponding patterns, occasionally investigated through connectionist models, in which stable states of mind are related to virtues and mindfulness ${ }^{55,56}$.

Something similar can be done regarding religious experiences. This field of study is usually called neurotheology. A more precise name would be neurobiology of religious and spiritual experiences ${ }^{57}$. Different neurotheological perspectives range from reductionistic views, which propose that these experiences, such as mysticism, meditation, and religious beliefs, are merely a product of particular brain states and activations, to an account of different psychological states (cognitive, emotional, and behavioral) based upon special brain circuits and associated with religious acts that are considered to be an authentic anthropological dimension related to God.

This field is very wide and complex. Religious acts, like any other human performance, have certainly a neural substrate, although it may not necessarily be specific. These acts, which can be very different and can be realized in various ways, can exercise a downward causation upon brain circuits (motivational, cognitive, 
emotional). Inversely, particular neurophysiological states modulating moods, motivations, etc., can develop an upward causation that affects the way specific religious acts are experienced by individuals or groups.

The relationship between theology and neuroscience is in some way similar to the relationship between theology and psychology of religion. But the claim that neuroscience explains religion would be analogous to claiming that neuroscience explains mathematics, literature, philosophy, an so on. Neuroscience is an important auxiliary discipline for the understanding of many aspects of human behavior, but it is not the key to a complete comprehension of man.

3.6. Enactivism, among whose proponents are to be listed Francisco Varela, Evan Thompson, Eleanor Rosch, and Alva Noë, can be considered a psychological and anthropological approach competing with the classical philosophies of mind. This latter had become overwhelmingly dominated by an isolationistic view of mind and brain $^{58}$. Such a perspective, typical of dualism, materialism, and functionalism, stands in stark contrast to enactivism, which emphasizes the active relationship of bodily agents, or humans, to the environment and to the world.

Enactivism rejects the representationist view of a brain primarily concerned with its own states and subjective representations. The brain is important, but it cannot be seen as a center endowed by cognitive powers that simply creates the world. The brain is a part of an organism, viewed as a complex system, and the mind is not only a function of the brain, but is an aspect of the entire body (embodied mind). The unity of the embodied mind and brain is "extended" to the world through action (enactive mind), while at the same time the world appears to the agent as functionally patterned in accordance with his or her needs, capacities, and experiences $^{59}$. Reducing the human being to the brain is parallel to the Cartesian reduction of man to consciousness.

Thomas Fuchs (1978-), a German philosopher and psychiatrist endorsing enactivist claims, presents a philosophy of neuroscience in which the brain is understood as a relational organ rather than a mere information processor ${ }^{60}$. It is an organ of the person, and not the seat of consciousness or of a mind. Its function is to integrate experiences so as to regulate and modulate the entire organism, to transform 
information, and to enable communication with others while simultaneously mediating the various cycles of organism-environment interactions. Biological plasticity enables the brain to be in a continuous process of transformation, flowing from the interactions of the person with the physical environment, culture, ideas, and other persons. The brain is an organ of possibilities that are accomplished through neural processes and whose agent is the human person. The plastic condition of the brain enables the individual to grow as a person through experience and to create his or her own personal history. The person -not the brain- thinks, lives, and interacts with the world, thanks to brain activity. Fuchs strongly criticizes Thomas Metzinger's thesis according to which the Self would be a purely phenomenic construction of the brain $^{61}$.

Fuchs follows a phenomenological approach in a broad sense of the word, coherent with the enactivist premises in psychopathology. Mental disorders, he argues, must be seen in all of their dimensions, as they disrupt the unity of the person and his or her relationships with the environment. Psychiatric therapies should be both biological and psychological ${ }^{62}$. Contrary to the methodology of reductionism, the therapists in this field should bear in mind the circular complex causality within a systemic biological framework. Any single interaction within the system has holistic effects at all levels.

Interventions and psychiatric treatment are efficacious, according to Fuchs, whenever they follow the systemic and ecological concept of mind and brain ${ }^{63}$. This idea implies a comprehension of the interconnection between psychological, social, and pharmacological approaches. Psychological therapies influence the structure and functions of the brain by altering synaptic plasticity and gene expression, following a top-down causality. Conversely, neuropsychological and biochemical dysfunctions influence moods, emotions, and ways of perception, exercising a bottom-up causality.

This is a circular complex causal process displayed between the brain, the organism, mental or psychological states, and interactions with the environment, with the brain acting as a mediating entity ${ }^{64}$. There is no separation, but rather a reciprocal transformation or translation between psychological and biological processes. Depression, for instance, is seen by Fuchs as a psychophysiological desynchronization ${ }^{65}$. Here a loss with which the individual is unable to cope is 
translated by the brain into a neurobiochemical pattern affected by the uncoupling of rhythmic physiological processes, which in turn increases depressed mood. Every level triggers and influences the other. Analogous views can be supported regarding schizophrenia and many other mental disorders ${ }^{66}$. The classic positions in philosophy of mind examined in the first part of this chapter, such as dualism and functionalism, are unable to obtain these insights into psychopathology.

\section{Conclusion}

Among the many conclusions one can draw from the delineation of the different positions enumerated in these pages, two considerations can be proposed. The first is epistemological. Neurobiology, as far as it is concerned with human capacities, such as language, reasoning, understanding, and free decisions and actions, is not purely biological. It is a hybrid science that presupposes and employs anthropological and ethical knowledge $\mathrm{e}^{67}$. This epistemological feature is unique in neuroscience. It entails a complementary interaction between the anthropological (as well as psychological) and the biological perspectives. As a purely biological science, neuroscience involves a partial and not a total explanation.

The second consideration is ontological and is the basis of the former. The human person, and in a different way, animals as well, is a multi-layered complex and systemic unity. Each level, the vegetative, the sensitive to various degrees, and the rational, possesses its own autonomy while at the same time it influences the others, not extrinsically, but essentially, according to the various modes of integration. An important way of integration could be understood following the hylomorphic Aristotelian model (taken in a broad sense) that explains how higher levels are capable of giving a new sense to lower and more material levels while at the same time depending upon the material conditions of the former ${ }^{68}$. Such is analogous to the game of chess, wherein intelligent moves and the rules of the game provide a new dynamism to the physical chess pieces, which otherwise merely obey gravitational and other physical laws. Accordingly, there are many senses of being causally influent, in several reciprocal directions.

The limits of dualism, materialism, and functionalism are overcome thanks to this systemic view ${ }^{69,70}$. The final pages of this chapter were dedicated to enactivism 
and to Fuchs' view because this approach seems more complete and promising than the others. The Aristotelian framework, as understood in hylomorphism, and the complex unity of the human person adds only a more comprehensive ontological view to this perspective.

\section{References}

1. Bickle J, Mandik P, Landreth A. The philosophy of neuroscience. In: The Stanford Encyclopedia of Philosophy. Summer 2012 Edition, Zalta EN, editor. [On-line Encyclopedia] [Accessed July 20, 2014, at http://plato.stanford.edu/archives/sum2012/entries/neuroscience].

2. Lowe EJ. An introduction to the philosophy of mind. Cambridge: Cambridge University Press; 2000.

3. Heil J. Philosophy of mind. A contemporary introduction. $3^{\text {rd }}$ ed. New York, London: Routledge; 2013.

4. Kim J. The philosophy of mind. $3^{\text {rd }}$ ed. Boulder (CO): Westview Press; 2010.

5. Robinson H. Dualism. In: The Stanford Encyclopedia of Philosophy. Winter 2012 Edition, Zalta EN, editor. [On-line Encyclopedia] [Accessed July 20, 2014, at http://plato.stanford.edu/archives/win2012/entries/dualism].

6. Meixner U. The two sides of being: A reassessment of psycho-physical dualism. Paderborn: Bonifatius; 2004.

7. Ramsey W. Eliminative materialism. In: The Stanford Encyclopedia of Philosophy. Summer 2013 Edition, Zalta EN, editor. [On-line Encyclopedia] [Accessed July 20, 2014, at http://plato.stanford.edu/archives/sum2013/entries/materialism-eliminative].

8. Churchland PS. Neurophilosophy. Cambridge (Mass.): The MIT Press; 1986.

9. Churchland PS. Brain-Wise. Cambridge (Mass.): The MIT Press; 2002.

10. Murphy N. 2011. Avoiding neurobiological reductionism. The role of downward causation in complex systems. In: Sanguineti JJ, Acerbi A, Lombo 
JA, editors. Moral Behavior and Free Will. Morolo (FR), Italy: IF Press; 2011. p. 201-222.

11. Stoljar D. Physicalism. In: The Stanford Encyclopedia of Philosophy, Fall 2009 Edition, Zalta EN, editor. [On-line Encyclopedia] [Accessed July 20, 2014, at http://plato.stanford.edu/archives/fall2009/entries/physicalism].

12. Agazzi E. Scientific objectivity and its contexts. New York: Springer; 2014.

13. Tye M. Qualia. In: The Stanford Encyclopedia of Philosophy, Fall 2013 Edition, Zalta EN. Editor. [On-line Encyclopedia] [Accessed July 20, 2014, at http://plato.stanford.edu/archives/fall2013/entries/qualia].

14. Ryle G. The concept of mind. Chicago: The University of Chicago Press; 2000.

15. McLaughlin B, Bennett K. Supervenience. In: The Stanford Encyclopedia of Philosophy. Spring 2014 Edition, Zalta EN, editor. [On-line Encyclopedia] [Accessed July 20, 2014, at http://plato.stanford.edu/archives/spr2014/entries/supervenience].

16. Horst S. Computational theory of mind. In: The Stanford Encyclopedia of Philosophy. Spring 2011 Edition, Zalta EN, editor. [On-line Encyclopedia] [Accessed July 20, 2014, at http://plato.stanford.edu/archives/spr2011/entries/computational-mind].

17. Levin J. Functionalism. In: The Stanford Encyclopedia of Philosophy. Spring 2011 edition, Zalta EN, editor. [On-line Encyclopedia] [Accessed July 20, 2014, at http://plato.stanford.edu/archives/fall2013/entries/functionalism].

18. Clayton $\mathrm{Ph}$, Davies $\mathrm{P}$, editors. The re-emergence of emergence. Oxford: Oxford University Press; 2006.

19. Popper K, Eccles JC. The self and its brain. New York: Routledge; 1983.

20. Bunge M. The Mind-body problem. A psychobiological approach. Oxford: Pergamon Press; 1980. 
21. Searle J. 2004. Mind: A brief introduction. Oxford: Oxford University Press, 2004.

22. Moya JC. Mind, brain, and downward causation. In: Sanguineti JJ, Acerbi A, Lombo JA, editors. Moral Behavior and Free Will. Morolo (FR), Italy: IF Press; 2011. p. 185-200.

23. Nasrallah HA. The antipsychiatry movement: Who and why. Current Psychiatry. December 2011; (10): 4, 6, 53.

24. Auletta G, Colagé I, D'Ambrosio P. A critical assessment of transhumanism. Acta Philosophica. 2013; (22): 327-348.

25. Popper K, Eccles JC. The self and its brain. $2^{\text {nd }}$ Part: p. 225-406 (by Eccles). New York: Routledge; 1983.

26. Sherrington ChS. Man on his nature. $2^{\text {nd }}$ ed. Cambridge: Cambridge University Press; 1951.

27. Sperry RW. Mind-Brain interaction: Mentalism, yes; dualism, no. Neuroscience. February 1980; 5: 195-206.

28. Eccles JC. How the self controls its brain. Berlin: Springer; 1994.

29. Gazzaniga MS, LeDoux J. The integrated mind. New York: Plenum Press; 1978.

30. Gazzaniga, MS. Mind matters. Boston: Houghton Mifflin; 1988.

31. Gazzaniga, MS. Human. The science behind what makes us unique. New York: Harper Collins; 2008.

32. Gazzaniga, MS, 1998. The mind's past. Berkeley: University of California Press.

33. Changeux JP. Du vrai, du beau, du bien. Une nouvelle approche neuronale. Paris: Odile Jacob; 2008.

34. Changeux JP. Neuronal man. Princeton: Princeton University Press; 1997. 
35. Changeux JP, Ricoeur P. 2002. What makes us think. Princeton: Princeton University Press; 2002.

36. Bennett MR, Hacker PMS. Philosophical foundations of neuroscience. Oxford: Blackwell; 2003.

37. Bennett MR, Hacker PMS. History of cognitive neuroscience. Oxford: WileyBlackwell; 2008.

38. Damasio A. The feeling of what happens. Orlando (Florida): Harcourt; 1999.

39. Damasio A. Looking for Spinoza. Orlando (Florida): Harcourt; 2003.

40. Edelman G. Neural darwinism: The theory of neuronal group selection. New York: Basic Books; 1987.

41. Edelman G. The remembered present: A biological theory of consciousness. New York: Basic Books; 1990.

42. Tononi G. An information integration theory of consciousness. BMC Neuroscience. 2004; 5 (42). Doi: 10.1186/1471-2002-5-42.

43. Tononi G. Consciousness as integrated information: A provisional manifesto. Biol. Bull. 2008; (215): 216-242.

44. Tononi G, Koch C. The neural correlates of consciousness. An update. Ann. N.Y. Acad. Sci. 2008; (1124): 239-261. Doi: 10.1196/annals.1440.004.

45. LeDoux J. Synaptic self. New York: Penguin; 2003.

46. Panksepp J. Affective neuroscience. Oxford: Oxford University Press; 2005.

47. Libet B. Unconscious cerebral initiative and the role of conscious will in voluntary action. The Behavioral and Brain Sciences. 1985; (8): 529-566.

48. Rizzolatti G, Sinigaglia C. 2008. Mirrors in the brain. How we share our actions and emotions. Oxford: Oxford University Press; 2008.

49. Iacoboni M. Mirroring people. New York: Picador USA; 2009. 
50. Ramachandran VS. Mirror neurons and imitation learning as the driving force behind 'the great leap forward' in human evolution [Edge Foundation Web Site; 6-1-2000] [Accessed July 20, 2014, at http://edge.org/3rd_culture/ramachandran/ramachandran_index.html].

51. Moll J., Eslinger PJ, De Oliveira-Souza R. Frontopolar and anterior temporal cortex activation in a moral judgment task: preliminary functional MRI results in normal subjects. Arquivos de Neuro-Psiquiatria. 2001; (59): 657-664.

52. Casebeer WD. Moral cognition and its neural constituents. Nature Reviews Neuroscience. 2003; (4): 840-847.

53. Casebeer WD. Neurobiology supports virtue theory on the role of heuristics in moral cognition. Behavioral and Brain Sciences. 2005; (28): 547-548.

54. Glannon W. Brain, body, and mind. Oxford: Oxford University Press; 2011.

55. Reimer KS, Spezio ML, Brown WS, Van Slyke J, Peterson GR. Virtuous courage: New methods for the interdisciplinary study of virtue. In: Monroe KR. Science, ethics, and politics: Conversations and investigations. Boulder (CO):Paradigm Press; 2011.p. 70-85.

56. Spezio ML. Social neuroscience and theistic evolution: Intersubjectivity, love, and the social sphere. Zygon. June 2013; (48): 428-438. Doi: 10.111/zygo.12005.

57. Newberg AB, Lee BY. The Neuroscientific study of religious and spiritual phenomena: Or why God doesn't use biostatistics. Zygon. June 2005; (40): 469-489.

58. Noë A. Out of our heads. New York: Hill and Wang; 2009.

59. Noë A. Action in perception. Cambridge (Mass): The MIT Press; 2004.

60. Fuchs Th. Das Gehirn -ein Beziehungsorgan. Eine phänomenologischökologische Konzeption. Kohlhammer: Stuttgart; 2009. 
61. Metzinger Th. The Ego tunnel. The science of the mind and the myth of the self. New York: Basic Books; 2009.

62. Fuchs Th. Are mental illnesses diseases of the brain? In: Choudhury S, Slaby J, editors. Critical Neuroscience: A handbook of the social and cultural contexts of neuroscience. Oxford: Wiley-Blackwell; 2012. p. 331-344.

63. Fuchs Th. Ökologie des Gehirns. Eine systemische Sichtweise für die Psychiatrie. Nervenarzt. 2005; (76):1-10.

64. Fuchs Th. Embodied cognitive neuroscience and its consequences for psychiatry. Poiesis and Praxis. 2009; (6): 219-233. Doi: 10.1007/s10202-0080068-9.

65. Fuchs Th. Melancholia as a desynchronization. Towards a psychopathology of interpersonal time. Psychopathology. 2001; (34):179-186.

66. Fuchs Th. Selbst und Schizophrenie. Deutsche Zeitschrift für Philosophie. 2012; (60): 887-901.

67. Sanguineti JJ. Neuroscience, philosophical relevance of. In: New Catholic Encyclopedia Supplement 2012-2013: Ethics and Philosophy, vol. 3. Fastiggi RL, editor. Detroit: Gale, p. 1065- 1068.

68. Madden JD. Mind, matter \& nature. Washington: The Catholic University of America Press; 2013.

69. Sanguineti, JJ 2011. Can free decisions be both intentional and neural operations? In: Sanguineti JJ, Acerbi A, Lombo JA, editors. Moral Behavior and Free Will. Morolo (FR), Italy: IF Press; 2011. p. 149-168.

70. Sanguineti, JJ. Can the self be considered a cause? In: Auletta G, Colagè I, Jeannerod $\mathrm{M}$, editors. Brains top down. Is top-down causation challenging neuroscience? Singapore: World Scientific; 2013. p. 121-142. 